\title{
Point mutation and polymorphism in Duchenne/Becker Muscular Dystrophy (D/BMD) patients
}

\author{
LS Chaturvedi ${ }^{1,2}$, M Mukherjee $^{1}$, \\ S Srivastava ${ }^{1,3}$, RD Mittal ${ }^{4}$ and B Mittal ${ }^{1,5}$ \\ ${ }^{1}$ Department of Medical Genetics, Sanjay Gandhi Postgraduate \\ Institute of Medical Sciences, Raebareli Road, Lucknow 226014, \\ India \\ ${ }^{2}$ Present address: Henry Ford Hospital, Detroit, USA \\ ${ }^{3}$ Present address: Rajiv Gandhi Cancer Hospital, New Delhi, India \\ ${ }^{4}$ Department of Urology, Sanjay Gandhi Postgraduate Institute of \\ Medical Sciences, Raebareli Road, Lucknow 226014, India \\ ${ }^{5}$ Corresponding author: Tel, +91-522-440004-8, ext. 2322; Fax, \\ +91-522-440 017; E-mail, balraj@sgpgi.ac.in, bml_pgi@yahoo. \\ com
}

Accepted 3 December 2001

Abbreviations: DMD, Duchenne muscular dystrophy; BMD, Becker muscular dystrophy; Mb, megabases; kb, kilobases; DNA, deoxyribonucleic acid; PCR, polymerase chain reaction; m-PCR, multiplex polymerase chain reaction; SSCA, single strand conformation analysis; HA, heteroduplex analysis; EMG, electromyography; Pm, promoter; MDE, mutation detection enhancement; LMP, low melting agarose; EDTA, ethylene diamine tetraacetic acid; TBE, tris borate EDTA

\begin{abstract}
Duchenne and Becker muscular dystrophies (D/BMD) are caused by mutations in the dystrophin gene. Two-thirds of patients have large intragenic deletions or duplications and the remaining one-third have point mutations, small deletions or insertions. Point mutations are more difficult to detect due to the enormous size $(2.4 \mathrm{Mb})$ of the gene and its large transcript (14 kb). In the present study, a total of 50 DNA samples from unrelated D/BMD (38 DMD and 12 BMD) patients who did not show intragenic deletions by multiplex PCR, were analyzed for detection of point mutations. Single stranded conformation analysis and heteroduplex analysis observed electrophoretic mobility shifts in one (BMD) and two (DMD and BMD) patients, respectively. The mobility shift and heteroduplexes were observed in exon 17 in all of the three patients. Sequencing of the amplified PCR products revealed a nucleotide change $(-37 \mathrm{~g}$ to $\mathrm{t})$ in the intronic region in two of the patients while a C2268T substitution in the exonic region in one. Mutation database search for D/BMD
\end{abstract}

mutations showed the nucleotide substitution in the exonic region as a novel change in the human dystrophin gene, which was not reported earlier. It resulted in an amino acid transition from threonine to methionine in the $687^{\text {th }}$ position of the dystrophin protein. This novel substitution has been included in the mutation database of Leiden muscular dystrophy pages (http://www.dmd.nl) in the rare polymorphism/mutation category. The substituted nucleotide segregated with the disease phenotype in the family suggesting that it can be directly used for carrier detection and prenatal diagnosis without identification of disease causing mutation.

Keywords: Duchenne/Becker muscular dystrophy, point mutation, polymorphism, dystrophin gene

\section{Introduction}

Duchenne/Becker muscular dystrophies (D/BMD) are the most frequent muscle diseases in children caused by mutations arising in the gene encoding dystrophin, a cytoskeletal protein. It is estimated to affect 1 in 3,500 newborn males worldwide (Emery, 1991). About 30-35\% cases of D/BMD are assumed to result from microdeletions, microinsertions or substitutions of one or more nucleotide(s). Several independent studies have reported small mutations in the dystrophin gene (Kiliman et al., 1992; Nigro et al., 1992, 1994; Roberts et al., 1992; Tuffery et al., 1993, 1995, 1996; Kneppers et al., 1995; Sitnik et al., 1997; Eranslan et al., 1999; Wibawa et al., 2000). These are randomly distributed throughout the dystrophin gene (http://www.dmd.nl).

Till date, 370 sequence variations have been identified in the human dystrophin gene and 177 mutations were found to be responsible for the disease (http:// www.dmd.nl). Most of the point mutations lead to premature translational termination due to nonsense (34\%), frameshift $(33 \%)$, splice site $(29 \%)$ and missense $(4 \%)$ mutations in the dystrophin gene (Rininsland and Reiss, 1994; Roberts et al., 1994; Barbieri et al., 1995; Gardner et al., 1995; Prior et al., 1995; Winnard et al., 1995).

In the course of point mutation analysis in D/BMD patients, several sequence variations have been reported which do not cause any change in the gene size but cause minor substitutions. It is difficult to predict whether the observed change is a mutation or a rare polymorphism (Tuffery et al., 1992; Saad et al., 1994, 1997, 1998; Todorova and Daneili, 1997; Chen et al., 1998). 
In our laboratory more than $400 \mathrm{D} / \mathrm{BMD}$ patients have been registered so far. In about one third of patients, no detectable deletion was observed using m-PCR and Southern blotting, and was therefore presumed to have point mutations (Singh et al., 1997). In order to look for point mutations in the dystrophin gene, six exons of the dystrophin gene (5 proximal and 1 central regions) were screened by using Single Strand Conformation Analysis (SSCA) and Heteroduplex Analysis (HA) in 50 unrelated non-deletional D/BMD patients. Bands shifted in SSCA and $\mathrm{HA}$ were further analyzed by sequencing.

\section{Materials and Methods}

\section{Patients}

A total of 50 clinically confirmed unrelated non-deletional D/BMD patients (38 DMD and 12 BMD) from North India were subjected to point mutation analysis. Clinical diagnosis was based on EMG, Gower's sign, Pradhan's sign and calf hypertrophy (Sinha et al., 1992; Pradhan and Mittal, 1995). The deletion analysis was performed by m-PCR using 25 pairs of primers $(\mathrm{Pm}, 3,4,6,8,12$, $13,17,20,21,22,43,44,45,46,47,48,49,50,51,52$, 53,55 , and 60 ) of the dystrophin gene (Chamberlain et al., 1988; Beggs et al., 1990; Sinha et al., 1992; Singh et al., 1997). Mutation analysis was carried out using six exonic regions with flanking intronic sequences (Exons 4, 6, 8, 12, 17 and 44) in two triplex PCRs (Exons 6, 8, 17 and Exons 4, 12, 44).

\section{Single Strand Conformation Analysis (SSCA)}

The selected exons were amplified in two m-PCR with DNA samples of all 50 patients and two normal male individuals as controls. Five $\mu$ I PCR product (80-100 ng) of each patient and normal male individual were diluted with equal volumes of denaturing buffer ( $98 \%$ formamide, $10 \mathrm{mM}$ EDTA, 0.05\% bromophenol blue, 0.05\% xylene cyanol), denatured at $95^{\circ} \mathrm{C}$ and loaded on a $0.5 \mathrm{X}$ MDE $^{\mathrm{TM}}$ (Mutation detection enhancement) gel $(20 \times 40$ $\mathrm{cm}, 0.5 \mathrm{~mm}$ thick) prepared according to FMC Bioproducts protocol. The samples were run at a constant power of $6 \mathrm{~W}$ for $10 \mathrm{~h}$ at room temp in $0.6 \mathrm{X}$ TBE with or without $5 \%$ glycerol. The bands were visualized by silver staining.

\section{Heteroduplex Analysis (HA)}

The selected exons were amplified in two m-PCR with DNA samples of the patients and two normal male individuals as controls. Five $\mu \mathrm{l}$ of PCR product (80-100 $\mathrm{ng}$ ) of each patient was mixed with an equal amount of control product, denatured at $95^{\circ} \mathrm{C}$ for 5 min and reannealed at $37^{\circ} \mathrm{C}$ for $1 \mathrm{~h}$. Five $\mu \mathrm{l}(30-35 \mathrm{ng})$ of reannealed fragments were mixed with double dye (30\% sucrose, $0.05 \%$ bromophenol blue and $0.05 \%$ xylene cyanol) and loaded onto a $1 \mathrm{X}$ MDE gel $(20 \times 40 \mathrm{~cm}, 1 \mathrm{~mm}$ thick). Electrophoresis was carried out at a constant voltage of $600 \mathrm{~V}$ for $8 \mathrm{~h}$ at room temperature in $0.6 \mathrm{XTBE}$ and the bands were visualized by silver staining.

\section{DNA Sequencing}

The PCR products were purified from low melting point (LMP) agarose and subjected to manual and automated sequencing. Manual sequencing of the purified PCR product was carried out using di-deoxy thermosequenase radiolabelled terminator cycle sequencing kit (Amersham Life Sciences). The sequencing gel was electrophoresed at $1700 \mathrm{~V}$ for $4 \mathrm{~h}$, fixed for $10 \mathrm{~min}$ in $10 \%$ acetic acid (v/v) containing $10 \%$ methanol $(\mathrm{v} / \mathrm{v})$, vacuum dried at $80^{\circ} \mathrm{C}$ for one $\mathrm{hr}$ and exposed to X-ray film (XOmat $\left.^{\mathrm{TM}}, \mathrm{XK}-5\right)$ for $24-36 \mathrm{~h}$ at $-80^{\circ} \mathrm{C}$. The autoradiograms were developed and read carefully.

Automated sequencing (Applied Biosystems model $373 \mathrm{~A}$ ) of the purified PCR products was carried out using FS-Dye termination cycle sequencing ready reaction kit (Perkin Elmer, USA). At the completion of the reaction, the volume of reaction mix was raised to $100 \mu \mathrm{l}$ and phenolized once with phenol: chloroform (68:14). The aqueous layer was precipitated with ethanol and the pellet was washed with $70 \%$ ethanol and dried. It was then dissolved in $5 \mu \mathrm{l}$ of formamide loading buffer, denatured and loaded onto a sequencing gel. Before loading the samples, the background fluorescence was measured and scan area was cleaned to get a uniform base line for all the sample lines. The samples were electrophoresed for $16 \mathrm{~h}$ at $40 \mathrm{~W}$. The sequence was obtained as an electropherogram. The nucleotide sequence so obtained was analyzed using PC-Gene software rel. 17.0 (Intelligenetics, USA). The BLAST program was used for analysis of nucleotide sequences.

\section{Results}

Out of 50 unrelated D/BMD patients analysed for point mutation detection, the electrophoretic mobility shift was observed in three patients: one by SSCP and two by HA. All three changes were observed in exon 17 (Figures 1,2$)$. Sequencing of the amplified PCR products confirmed the nucleotide alteration in all the three patients (Figures 3-5).

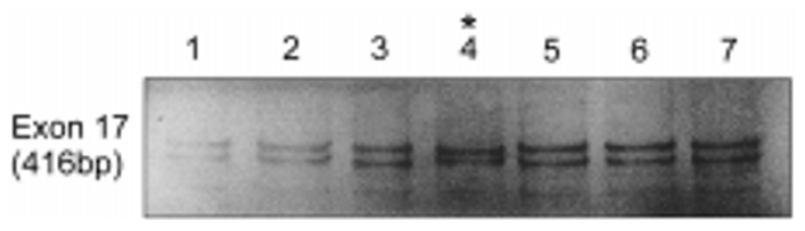

Figure 1. SSCA gel pattern of exon 17. Lanes 1 and 7, normal male controls. Lanes 2-6, D/BMD patients. Lane 4, mobility shift in MD-138 patient. 
I

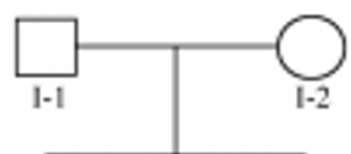

II

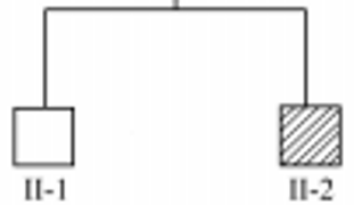

I-1 $\quad$ I-2 II-1 II-2

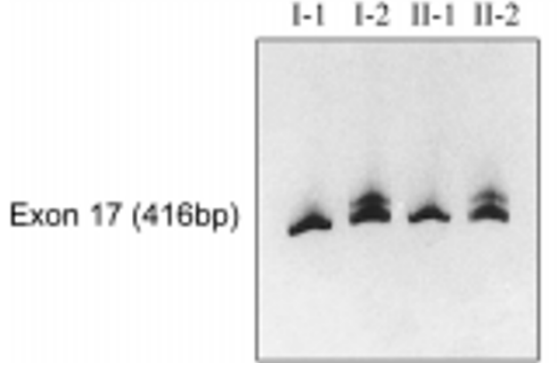

Figure 2. Pedigree and heteroduplex formation of exon 17 of MD-28.

SSCA showed a band shift only in exon 17 in one of the patients, MD-138 (BMD) (Figure 1). In the remaining 49 patients, no band shift was observed in any of the exons analysed. The manual dideoxy sequencing of exon 17 showed a substitution in the intronic region (-37 $\mathrm{g} \rightarrow \mathrm{t}$ ) in MD-138 when compared to the normal male control (Figure 3).

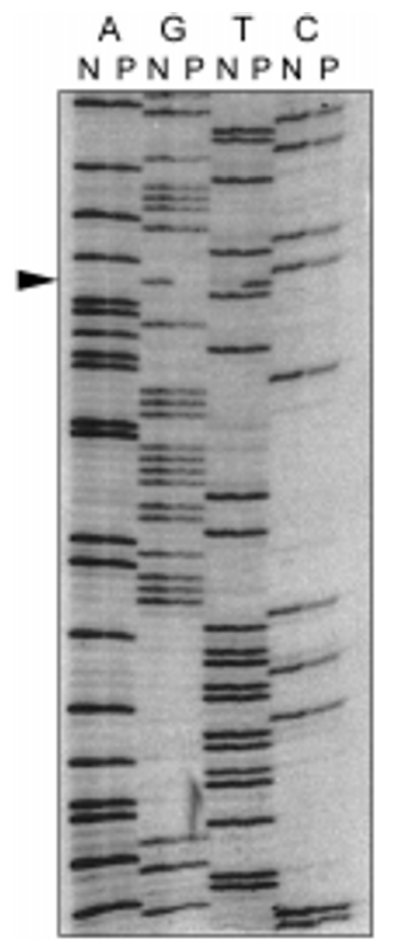

Figure 3. Manual DNA sequencing of exon 17 in control $(\mathrm{N})$ and MD-138 $(P)$. The arrow indicates the position of the nucleotide substitution $(-37 \mathrm{~g}$ to $\mathrm{t})$.

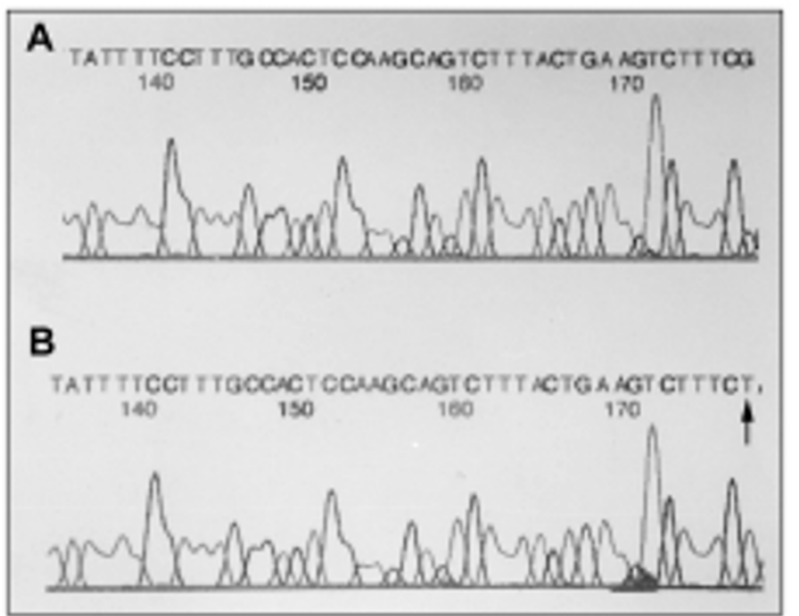

Figure 4. Automated DNA sequencing of exon 17 with flanking region $(A)$ normal male control and (B) MD-70. The arrow indicates the nucleotide substitution $(-37 \mathrm{~g}$ to $\mathrm{t})$ in intron 16 of the dystrophin gene at 2201 position.

The heteroduplex formation was observed in exon 17 in two patients, MD-28 and MD-70 (one DMD and one BMD respectively) (Figures 2). Automated DNA sequencing of exon 17 using fluorescent dideoxy dye termination showed a substitution in the intronic region (-37 $\mathrm{g} \rightarrow \mathrm{t}$ ) in the BMD patient, MD-70 (Figure 4). In case of MD-28, HA was further carried out in the DNA samples of mother, father and unaffected brother. In the mother, a heteroduplex formation was observed as in the proband (Figure 2). Automated DNA sequencing showed a substitution (transition) in the exonic region at $68^{\text {th }}$ nucleotide position of exon 17 (C2268T) of the dystrophin gene. Sequencing the PCR products of father, unaffected son, mother and normal male control revealed that the father and son had no change in the sequence but the mother was heterozygous for the change (Figure 5). In the remaining patients, no heteroduplex formation was observed in the other exons. The results of BLAST searches are shown in Figure 6.

\section{Discussion}

Several independent investigators have used different methods to search for point mutations in the dystrophin gene in $30 \%$ of D/BMD patients. SSCA (Orita et al., 1989; Glavac and Dean, 1993) and HA (Glavac and Dean, 1995) are mutation detection techniques that rely on detecting changes in the physical properties of DNA caused by the presence of sequence changes. These methods have shown an efficiency of $7-27 \%$ depending on the conditions and exons analysed (Soto and Sukumar, 1992; White et al., 1992; Kneppers et al., 1995; Eranslan et al., 1999). Prior et al. (1995) screened around $80 \%$ of the dystrophin coding sequences for small mutations by using HA in 158 patients and identified mutations in 29 


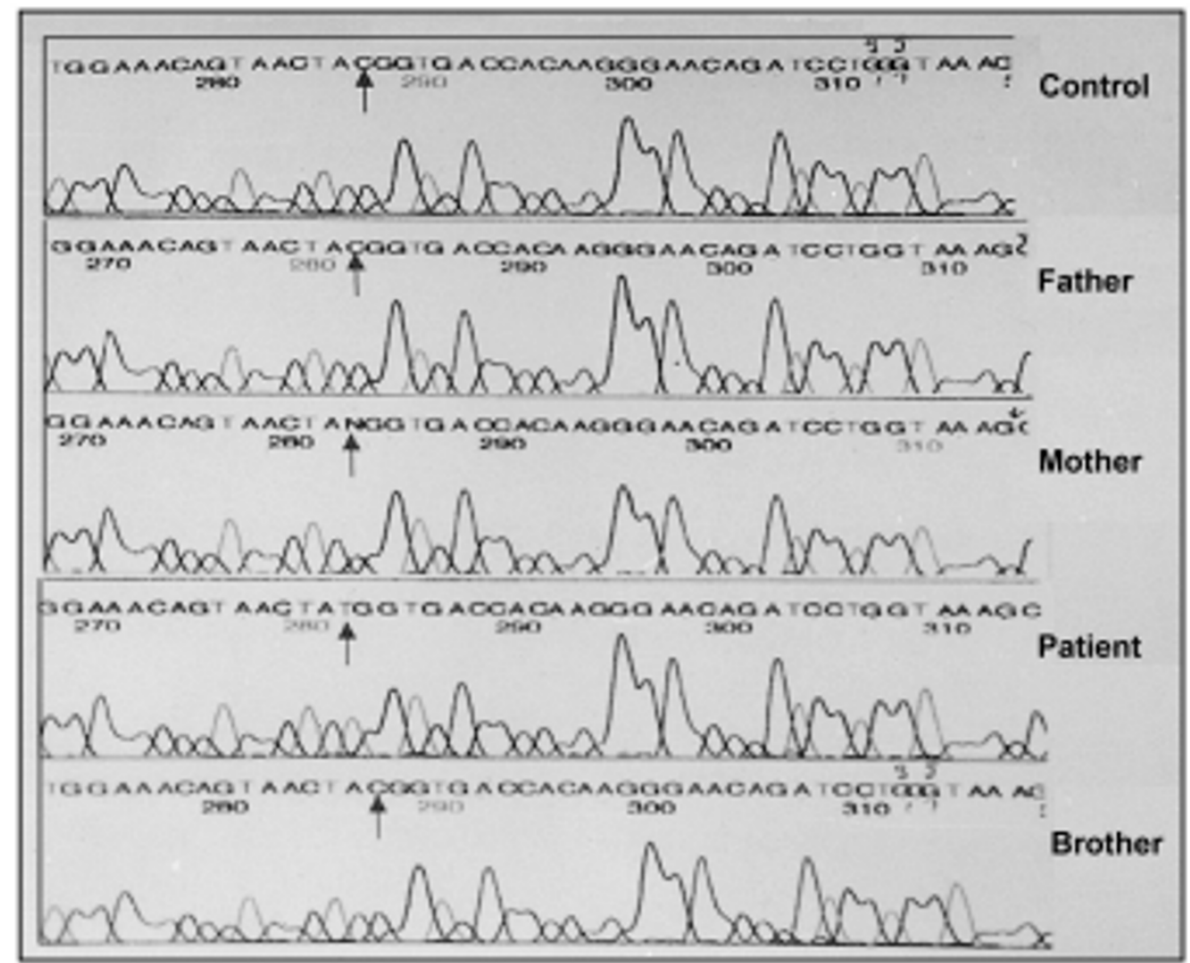

Figure 5. Automated DNA sequencing of exon 17 of normal male control and members of family, MD-28. The arrow indicates the nucleotide substitution C2268T in the exonic region of the patient, the heterozygous condition in the mother and normal sequence in the father and unaffected brother.

A

Query: 1 cagccatcactaacacagacaactgtaatggaaacagtaactatggtgacca 52

111111111111111111111111111111111111111111111111

Sbject: 2225 cagccatcactaacacagacaactgtaatggaaacagtaactacggtgacca 2276

B

5 ?

3'

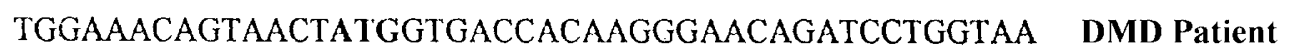

TGGAAACAGTAACTACGGTGACCACAAGGGAACAGATCCTGGTAA Human

TGGAAACAGTAACTATGGTGACCACAnGGGAACAGATCCTGgtaA Chicken

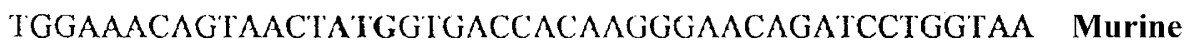

Figure 6. BLAST searches. (A) Homology of the sequenced exon 17 of patient MD-28 with a normal human dystrophin sequence. (B) Comparison of the above sequence with human, chicken and murine dystrophin exon 17.

of them. They concluded that in many of the DMD and majority of BMD, small mutations lie in the non-coding regions of the gene. Eranslan et al. (1999) screened 18 deletion-prone exons (25.5\% of the coding region) of the dystrophin gene by using non-isotopic multiplex SSCA in 56 unrelated non-deletional D/BMD patients. They 
identified 5 diseases causing mutations and 6 polymorphisms in Turkish D/BMD patients.

In the present study, sequencing showed a nucleotide substitution of $G$ to $T$ in the intronic region (2201-37G/ $\mathrm{T}$ ) in two patients (MD-138 and MD-70) and a nucleotide substitution in the exon 17 (C2268T) in one (MD28). The observed intronic nucleotide change in the dystrophin gene has been reported earlier by many independent investigators (Kiliman et al., 1992; Tuffery et al., 1992; Nigro et al., 1994; Prior et al., 1995; Sitnik et al., 1997). They have observed this not only in D/ BMD patients but also in normal individuals, thereby constituting a rare polymorphism. The possibility of it being involved in the pathogenesis of the disease is ruled out since it is away from the splice site.

In MD-28 the nucleotide substitution (C2268T) in the exon 17 resulted in an amino acid alteration from threonine to methionine at the 687th position of the dystrophin protein. The sequence homology analysis using BLAST depicted that the substituted nucleotide is present in chicken and murine dystrophin gene. Therefore, this change does not appear to be conserved across species. Thus, it suggests that this change may not be responsible for the disease but appears to be a polymorphism. In the family of MD-28, the mother was found to be heterozygous for the C2268T nucleotide substitution. The sequence analysis showed that the substituted nucleotide was inherited with the disease phenotype.

\section{Acknowledgements}

The authors are grateful to the Director, Sanjay Gandhi PGIMS and Head of the Medical Genetics Department for providing the necessary facilities. We are thankful to Dr. Prabodh Tewari, NBRI for helping us with automated sequencing. Two of us (SS and MM) are thankful to Council of Scientific and Industrial Research, New Delhi, for awarding research fellowships.

\section{References}

Barbieri AM, Soriani N, Tubeillo GM, Ferrari M, Carrera P. A nonsense mutation (Gln-637-Term) in exon 17 of the dystrophin gene detected by heteroduplex analysis. Hum Genet 1995;96:343-44

Beggs AH, Koening M, Boyce FM, Kunkel LM. Detection of $98 \%$ of DMD/BMD gene deletions by polymerase chain reaction. Hum Genet 1990;86:45-48

Chamberlain JS, Gibbs RA, Ranier JE, Nguyen PN, Caskey C. Deletion screening of the Duchenne muscular dystrophy locus via multiplex DNA amplification. Nucl Acid Res 1988;16:11141-56
Chen B, North PE, Parahm DM. Implications of a common polymorphism in intron 12 of the dystrophin gene for deletion detection by multiplex PCR. Gene 1998;209:211-17

Emery AEH. Population frequencies of inherited neuromuscular diseases-a world survey. Neuromuscul Disord. 1991;1:19-20

Eranslan S, Kayserili H, Apak MY, Kirdar B. Identification of point mutations in Turkish DMD/BMD families using multiplexsingle stranded conformation analysis (SSCA). Eur J Hum Genet 1999;7:765-70

Gardner RJ, Bobrow M, Roberts RG. The identification of point mutations in Duchenne muscular dystrophy patients using reverse transcript PCR and the protein truncation test. Am J Hum Genet 1995;57:311-20

Glavac D, Dean M. Optimization of the single-strand conformation polymorphism (SSCP) technique for detection of point mutations. Hum Mutat 1993;2:404-14

Glavac D, Dean M. Applications of heteroduplex analysis for mutation detection in disease genes. Hum Mut 1995;6:281-87

Kiliman MW, Pizzuti A, Grompe M, Caskey CT. Point mutations and polymorphisms in the human dystrophin gene identified in genomic DNA sequences amplified by m-PCR. Hum Genet 1992;89:253-58

Kneppers ALJ, Deutz-Terlouw PP, den Dunnen JT, van Ommen GJB, Bakker E. Point mutation screening for 16 exons of the dystrophin gene by multiplex single strand conformation polymorphism analysis. Hum Mutat 1995;5:23542

Nigro V, Nigro, G, Esposito, MG, Comi LI, Molinari AM, Puca GA, Politano L. Novel small mutations along the DMD/BMD gene associated with different phenotypes. Hum Mol Genet 1994;3:1907-908

Nigro V, Politano L, Nigro G, Romano SC, Molinari AM, Puca GA. Detection of a nonsense mutation in the dystrophin gene by multiple SSCP. Hum Mol Genet 1992;1:517-20

Orita M, Hiroyuki I, Kanazawa H, Hayashi K, Sekiya T. Detection of polymorphisms of human DNA gel electrophoresis as single- strand conformation polymorphisms. Proc Natl Acad Sci USA 1989;86:2766-70

Pradhan S, Mittal B. Infraspinatus muscle hypertrophy and wasting of axillary folds as the important sign in Duchenne muscular dystrophy. Clin Neurol Neurosurg 1995;97:134-38

Prior TW, Bartolo C, Pearl DK, Papp AC, Snyder PJ, Sedra MS, Burghes AH, Mendell JR. Spectrum of small mutations in the dystrophin coding region. Am J Hum Genet 1995;57:22-33

Rininsland F, Reiss J. Microlesions and polymorphisms in the Duchenne/Becker muscular dystrophy gene. Hum Genet 1994;94:111-16

Roberts RG, Bobrow M, Bentley DR. Point mutations in dystrophin gene. Proc Natl Acad Sci USA 1992;89:2331-35

Roberts RG, Gardner RJ, Bobrow M. Searching for the 1 in $2,400,000$ : a review of dystrophin gene point mutations. Hum Mutat 1994;4:1-11

Saad FA, Merlini L, Mostacciuolo ML, Danieli GA. Double 
missense mutation in exon 41 of the human dystrophin gene detected by double strand conformation analysis. Am J Med Genet 1998;80:99-102

Saad FA, Mostacciuolo ML, Trevisan CP, Tomelleri G, Angelini C, Abdel Salam E, Danieli GA. Novel mutations and polymorphisms in the human dystrophin gene detected by doublestrand conformation analysis. Hum Mutat 1997;9:188-90

Saad FA, Vita G, Toffolatti L, Danieli GA. A possible missense mutation detected in the dystrohpin gene by Double-Strand Conformation Analysis (DSCA). Neuromuscul Disord 1994; 4(4):335-41

Singh V, Sinha S, Mishra S, Chaturvedi LS, Pradhan S, Mittal $\mathrm{RD}$, Mittal B. Proportion and pattern of dystrophin gene deletions in North Indian Duchenne and Becker muscular dystrophy patients. Hum Genet 1997;99:206-208

Sinha S, Pradhan S, Mittal RD, Mittal B. Detection of gene deletion in patients of Duchenne muscular dystrophy/Becker muscular dystrophy using polymerase chain reaction. Indian $\mathrm{J}$ Med Res 1992;96:297-301

Sitnik R, Campiotto S, Vainzof M, Pavanello RC, Takata RI, Zatz M, Passos-Bueno MR. Novel point mutations in the dystrophin gene. Hum Mutat 1997;10:217-22

Soto D, Sukumar D. Improved detection of mutations in the p53 gene in human tumors as single stranded conformation polymorphisms and double-stranded heteroduplex DMD. PCR Methodsm App. 1992;2:96-98

Todorova A, Daneili GA. Large majority of single- nucleotide mutations along the dystrophin gene can be explained by more than one mechanism of mutagenesis. Hum Mutat 1997; 9:537-47
Tuffery S, Bareil C, Demaille J, Claustres M. Four novel dystrophin point mutations: detection by the protein truncation test and transcript analysis in lymphocytes from Duchenne muscular dystrophy patients. Eur J Hum Genet 1996;4:143-52

Tuffery S, Demaille J, Claustress M. A new intragenic polymorphism detected by the single-strand conformation polymorphism (SSCP) assay in the dystrophin gene. Hum Mutat 1992;1:221-23

Tuffery S, Lenk U, Roberts RG, Demaille J, Claustres, M. Protein truncation test: analysis of two novel point mutations at the carboxy-terminus of the human dystrophin gene associated with mental retardation. Hum Mutat 1995;6:126-35

Tuffery S, Moine P, Demaille J, Claustres M. Base substitutions in the human dystrophin gene: detection by using the single-strand conformation polymorphism (SSCP) technique. Hum Mutat 1993;2:368-74

White MB, Carvalhom, Deres D, O'Brien SJ, Dean M. Detecting single base substitutions as heteroduplex polymorphisms. Genomics 1992;12:301-306

Wibawa T, Takeshima Y, Mitsuyoshi I, Wada H, Surono A, Nakamura $\mathrm{H}$, Matsuo M. Complete skipping of exon 66 due to novel mutations of the dystrophin gene was identified in two Japanese families of Duchenne muscular dystrophy with severe mental retardation. Brain Dev 2000;22:107-12

Winnard AV, Mendell JR, Prior TW, Florence J, Burghes AH. Frameshift deletions of exons 3-7 and revertant fibers in Duchenne muscular dystrophy: mechanisms of dystrophin production. Am J Hum Genet 1995;56:158-66 